\title{
A Corticotropin Releasing Factor Pathway for Ethanol Regulation of the Ventral Tegmental Area in the Bed Nucleus of the Stria Terminalis
}

\author{
Yuval Silberman, ${ }^{1,4}$ Robert T. Matthews, ${ }^{1,3,4}$ and Danny G. Winder ${ }^{1,2,3,4}$ \\ ${ }^{1}$ Department of Molecular Physiology and Biophysics, ${ }^{2}$ Vanderbilt Brain Institute, ${ }^{3}$ Kennedy Center for Research on Human Development, Vanderbilt \\ University School of Medicine, and ${ }^{4}$ Neuroscience Program in Substance Abuse (N-PISA), Nashville, Tennessee 37232
}

\begin{abstract}
A growing literature suggests that catecholamines and corticotropin-releasing factor (CRF) interact in a serial manner to activate the bed nucleus of the stria terminalis (BNST) to drive stress- or cue-induced drug- and alcohol-seeking behaviors. Data suggest that these behaviors are driven in part by BNST projections to the ventral tegmental area (VTA). Together, these findings suggest the existence of a CRF-signaling pathway within the BNST that is engaged by catecholamines and regulates the activity of BNST neurons projecting to the VTA. Here we test three aspects of this model to determine: (1) whether catecholamines modify CRF neuron activity in the BNST; (2) whether CRF regulates excitatory drive onto VTA-projecting BNST neurons; and (3) whether this system is altered by ethanol exposure and withdrawal. A CRF neuron fluorescent reporter strategy was used to identify BNST CRF neurons for whole-cell patch-clamp analysis in acutely prepared slices. Using this approach, we found that both dopamine and isoproterenol significantly depolarized BNST CRF neurons. Furthermore, using a fluorescent microsphere-based identification strategy we found that CRF enhances the frequency of spontaneous EPSCs onto VTA-projecting BNST neurons in naive mice. This action of CRF was occluded during acute withdrawal from chronic intermittent ethanol exposure. These findings suggest that dopamine and isoproterenol may enhance CRF release from local BNST sources, leading to enhancement of excitatory neurotransmission on VTA-projecting neurons, and that this pathway is engaged by patterns of alcohol exposure and withdrawal known to drive excessive alcohol intake.
\end{abstract}

\section{Introduction}

Addiction is a chronically relapsing disorder (Koob and Volkow, 2010). Recent studies show that inactivation of the bed nucleus of the stria terminalis (BNST) reduces both stress- and cue-induced reinstatement to drug seeking (Buffalari and See, 2011), suggesting that BNST activity is required for reinstatement. Catecholaminemediated activation of the BNST is critical for reinstatement, as stress increases norepinephrine (NE) release in the BNST (Pacak et al., 1995) and intracerebroventricular injections of NE induce reinstatement and increase BNST c-fos mRNA (Brown et al., 2011 ), while $\beta$-adrenergic receptor ( $\beta$-AR) blockade in the BNST reduces reinstatement (Leri et al., 2002). Further, $\beta$-AR activation in the BNST increases neuronal activity ex vivo (Egli et al., 2005; Nobis et al., 2011).

In addition to its effects on $\mathrm{NE}$ and c-fos expression, stress exposure also increases corticotropin-releasing factor (CRF)

\footnotetext{
Received June 21, 2012; revised Nov. 19, 2012; accepted Nov. 19, 2012.

Author contributions:Y.S. and D.G.W. designed research; Y.S. and R.T.M. performed research; Y.S. analyzed data; Y.S., R.T.M., and D.G.W. wrote the paper.

This work was funded by NIH Grants AA19455 (D.G.W.), DA19112 (D.G.W.), and AA20140 (Y.S.). We thank Katherine M. Louderback for summary model artistry as well as Dr. Sachin Patel and Dr. Tiffany Wills for their help with manuscript revisions. We also thank the Vanderbilt University Cell Imaging Shared Resource for help with imaging.

Correspondence should be addressed to Danny Winder, Department of Molecular Physiology and Biophysics, Vanderbilt University School of Medicine, Nashville, TN 37232. E-mail: danny.winder@vanderbilt.edu.

DOI:10.1523/JNEUROSCI.2949-12.2013

Copyright $\odot 2013$ the authors $\quad 0270-6474 / 13 / 330950-11 \$ 15.00 / 0$
}

mRNA in the BNST (Funk et al., 2006). Intra-BNST injection of CRF induces reinstatement (Erb and Stewart, 1999), while intraBNST injection of CRF receptor antagonists blocks stressinduced reinstatement (Erb and Stewart, 1999; Wang et al., 2006). Therefore, CRF may also increase BNST activity to induce reinstatement following a stressor. Furthermore, data suggest that NE-induced reinstatement is dependent on CRF signaling, while CRF-induced reinstatement is not dependent on AR signaling (Brown et al., 2009).

These studies suggest that stress may drive reinstatement via a serial process involving catecholamine initiation of BNST CRF signaling. Supporting this hypothesis, $\beta$-AR and dopamine (DA) receptor activation enhances excitatory neurotransmission in the BNST through a CRFR1-dependent mechanism (Kash et al., 2008b; Nobis et al., 2011). Recent findings using c-fos mapping suggest that BNST neurons projecting to the ventral tegmental area (VTA) (Georges and Aston-Jones, 2001; Massi et al., 2008), a brain region important in drug-seeking behaviors, may be more likely to be activated during reinstatement than other BNST neurons (Briand et al., 2010). Together, these data suggest a serial connection where catecholamines increase BNST CRF signaling, which in turn acts to enhance glutamatergic neurotransmission onto VTA-projecting BNST neurons to initiate reinstatement.

Although CRF signaling in the BNST is essential for relapse, the source of this CRF is not known as it could be released from local CRF neurons (Veinante et al., 1997) or from CRF-ergic afferents from other regions (Erb et al., 2001). It is also not clear 
how manipulations of the BNST CRF system might alter the excitability of BNST projection neurons, especially reinstatementcritical BNST neurons that project to the VTA. Moreover, the above described studies have focused on reinstatement to cocaine or morphine. While previous evidence suggests a role of CRF signaling in binge drinking (Lowery et al., 2010), ethanol (EtOH) withdrawal (Olive et al., 2002), and stress-induced reinstatement to EtOH seeking (Lê et al., 2000; Marinelli et al., 2007), no direct evidence indicates that chronic ethanol exposure can modulate neurocircuitry within the BNST that can potentially regulate reinstatement behaviors. Therefore, we sought to determine (1) whether catecholamines regulate CRF neurons in the BNST; (2) whether CRF modifies excitatory drive onto VTA-projecting BNST neurons; and (3) whether this system is altered by chronic intermittent ethanol exposure.

\section{Materials and Methods}

\section{Animals}

Two lines of mice were used in these studies. Seven- to twelve-week-old wild-type male C57BL/6J mice (The Jackson Laboratory) were used for all studies using retrograde tracer microinjections $(n=51)$. A CRFtomato reporter line of mice was used to easily identify CRF neurons for electrophysiology recordings (for details see below, Characterization of CRF-tomato mouse line). To reduce the number of transgenic mice needed in these studies, both male and female 6- to 12-week-old CRFtomato mice were used $(n=16)$. All mice were housed in groups of two to five for the duration of the studies. Food and water were available ad libitum. All procedures were approved by the Animal Care and Use Committee at Vanderbilt University (Nashville, TN).

\section{Characterization of CRF-tomato mouse line}

$C R F$-ires-cre mice were obtained from The Jackson Laboratory [strain B6(Cg)-Crhtm1(cre)Zjh/J, The Jackson Laboratory]. These mice were originally produced by the laboratory of Z. Josh Huang (Cold Spring Harbor Laboratory, Cold Spring Harbor, NY) (Taniguchi et al., 2011) and have cre expression directed by the endogenous $C r f$ promoter/enhancer elements. Upon arrival, CRF-ires-cre mice were then backcrossed for 1 generation further onto a C57BL/6J breeder line. Backcrossed CRF-ires-crepositive mice were then mated with a reporter line, ROSA-tomato (Madisen et al., 2010) [strain B6.Cg-Gt(ROSA)26Sor <tm14(CAG-tdTomato)Hze > $\mathrm{J}]$, in which a red (tomato) fluorescent protein is targeted to $\mathrm{cre}$-containing cells. The resultant offspring, CRF-tomato mice, were then used for subsequent studies.

For anatomical characterization, three CRF-tomato mice were overdosed with Nembutal (100 mg/kg, i.p.) and perfused through the left ventricle of the heart with ice-cold PBS (10 ml) followed by cold $4 \%$ paraformaldehyde in PBS $(20 \mathrm{ml})$. Brains were removed, postfixed for $24 \mathrm{~h}$ at $4^{\circ} \mathrm{C}$ in the same fixative, and then cryoprotected in PBS with $30 \%$ sucrose. Forty to fifty micrometer coronal sections of forebrain were cut on a cryostat (Leica CM 3050 S) and stored in PBS before fluorescent immunohistochemical staining. Free-floating brain sections containing the BNST, paraventricular nucleus of the hypothalamus (PVN), or central amygdala $(\mathrm{CeA})$ were washed in PBS $(4 \times 10 \mathrm{~min})$, permeabilized with $0.5 \%$ Triton X-100 in PBS (30 min), and then blocked with 10\% normal donkey serum in PBS containing 0.1\% Triton X-100 (1 h); all steps were at room temperature. Sections were then incubated with primary antibody in blocking solution for $48 \mathrm{~h}$ at $4^{\circ} \mathrm{C}$, followed by PBS washes $(4 \times 10 \mathrm{~min})$ and incubation with fluorescent dye-conjugated secondary antibodies for $24 \mathrm{~h}$ at $4^{\circ} \mathrm{C}$ in PBS with $0.1 \%$ Triton X-100. Finally, sections were washed $(4 \times 10 \mathrm{~min})$, mounted on slides, sealed with Aqua-Poly/Mount (Polysciences), and left overnight to dry. Stained sections of BNST, PVN, and CeA were imaged with a Zeiss 510 or 710 scanning confocal microscope. Images were analyzed with ZEN software (Carl Zeiss, Inc) or Image (NIH). MetaMorph software (Invitrogen) was used to enhance contrast and overlay images when needed.

\section{Identification of BNST neurons projecting to the VTA} and hypothalamus

Retrograde tracer microinjections. On the day of surgery, C57BL/6J (6- to 9 -week-old) mice were anesthetized with halothane (3\% initial, $1.5 \%$ for maintenance) and placed in a stereotaxic apparatus (my NeuroLab, Leica). Angle Two software was used for setting injection targets within the VTA (coordinates were $3.2 \mathrm{~mm}$ posterior to bregma, $0.5 \mathrm{~mm}$ lateral to the midline, and $4.8 \mathrm{~mm}$ below the skull surface) and the medial areas of the hypothalamus (coordinates were $0.82 \mathrm{~mm}$ posterior to bregma, $0.19 \mathrm{~mm}$ lateral to the midline, and $4.95 \mathrm{~mm}$ below the skull surface, with the needle path angled $10^{\circ}$ from the vertical plane). Other details about the surgical procedure have been described previously (Kash et al., 2009). For retrograde labeling of BNST neurons projecting to the VTA, the 33 gauge needle of a $10 \mu \mathrm{l}$ syringe was heat sterilized immediately before back filling with an undiluted suspension of fluorescent microspheres $(0.04 \mu \mathrm{m}$ diameter, red $(580 / 605)$ or dark red fluorescent $(660 / 680)$ FluoSpheres; Invitrogen). One hundred nanoliters of microsphere suspension was injected bilaterally at $10 \mathrm{nl} / \mathrm{min}$ using a UltraMicroPump II and Micro4 controller (World Precision Instruments). For retrograde labeling of BNST neurons that project to the hypothalamus, glass pipettes with tip diameters of $20-40 \mu \mathrm{m}$ were filled with a freshly made $3 \%$ solution of Fluorogold (FG; Fluorochrome) dissolved in cacodylate buffer, inserted into the hypothalamus, and the FG was microiontophoresed with $+1.5 \mu \mathrm{A}$ in a $7 \mathrm{~s}$ on/7 s off cycle that lasted for $6 \mathrm{~min}$. Ten minutes later, the pipette was withdrawn and the scalp wound was sutured closed. Postsurgical care included immediate subcutaneous saline $(1.0 \mathrm{ml}$ per $20 \mathrm{~g}$ of body weight) and analgesic (ketoprofen, $5 \mathrm{mg} / \mathrm{kg}$, s.c.) followed by additional ketoprofen injections every $24 \mathrm{~h}$ for 3-4 days. Animals that lost $>20 \%$ of their body weight or showed signs of uncontrolled pain, stress. or dehydration were euthanized. Six of fifty-one surgery animals were removed from the study for health concerns before experimentation. Healthy animals were used for anatomical ( $n=5$ mice), electrophysiological $(n=22)$ experiments 5-14 days after surgery or for chronic intermittent ethanol vapor chamber exposure and subsequent electrophysiological studies beginning 7-9 days after surgery $(n=19)$. The hind brains of all tracer-injected mice used for whole-cell recordings were immersion fixed in $4 \%$ paraformaldehyde/PBS, cryoprotected with $30 \%$ sucrose, and sectioned on a cryostat. Sections were mounted on slides and imaged with a fluorescence microscope (Nikon AZ100M).

Retrograde tracer localization. Methods for anatomical experiments of tracer-injected mice were identical to those described in the previous section for anatomical characterization of CRF-tomato mice. No primary antibody control sections from uninjected mice were used to show negligible nonspecific fluorescent signal from secondary antibodies and autofluorescence at microscope configurations used for collecting images. Control sections from tracer-injected mice, either unstained or stained with a single fluorophore, were used to show no significant crosstalk between fluorophores at microscope configurations used for collecting multicolor images. There was no bleed through of the native fluorescence of FG when bound to primary and secondary antibodies and then imaged with the microscope configuration used for NeuN/Cy2. Hypothalamus and VTA fluorescent tracers were examined in the BNST. The degree of potential fluorophore colocalization within the BNST was determined by assessing the total number of fluorescent-labeled cells in three successive BNST slices and determining the percentage of cells in which fluorescent markers overlapped in the group of labeled neurons. Cell counts were done with the aid of ImageJ or MetaMorph software. All animals with retrograde-labeled BNST neurons reported here were confirmed to have tracer injection sites in the VTA and/or hypothalamus (Fig. 3C,D for examples of injection sites).

\section{Chronic intermittent ethanol vapor chamber exposure paradigm}

Sham and chronic intermittent ethanol (CIE) mice were given a daily injection of pyrazole $(1 \mathrm{mmol} / \mathrm{kg})$ to impair the metabolism of ethanol. Thirty minutes after the injection, mice in their home cages were placed in a chamber filled with volatilized ethanol (CIE; $20.3 \pm 0.2 \mathrm{mg} / \mathrm{L}$ ) or volatilized water (sham). In a different cohort of mice, $60 \mathrm{mg} / \mathrm{kg}$ NBI27914 was included with the daily pyrazole injections to test the effect of a CRFR1 antagonist on CIE-induced alterations to BNST excitatory 
neurotransmission. Airflow through the chambers was maintained at 5.5 $\mathrm{L} / \mathrm{min}$, and volatilization was maintained at $1.5 \mathrm{~L} / \mathrm{min}$. Using these parameters, we can reliably obtain blood ethanol concentrations in the range of $150-185 \mathrm{mg} / \mathrm{dl}$ (Healey et al., 2008). After $16 \mathrm{~h}$ of exposure, mice were removed from the chambers and returned to standard animal housing facility. Mice were given two 4 day cycles of vapor chamber exposure ( $16 \mathrm{~h}$ in chambers per day, $8 \mathrm{~h}$ standard housing per day) separated by a 3 day period where they were maintained solely in standard animal housing facility. On the last day of the second CIE cycle the mice were returned to the standard animal housing facility for $4 \mathrm{~h}$ before being used for electrophysiology.

\section{Brain slice preparation and electrophysiology}

Three hundred-micrometer-thick brain slices containing the BNST (bregma, 0.14-0.26) were prepared from 7-12 week old C57BL/6J mice or from 6-12 week old CRF-tomato mice as described previously (Kash et al., 2008b; Nobis et al., 2011). Following dissection, slices were transferred to a holding chamber where they were heated $\left(27-30^{\circ} \mathrm{C}\right)$ and were allowed to equilibrate for at least $1 \mathrm{~h}$ before being transferred to a submerged perfusion chamber (also heated to $27-30^{\circ} \mathrm{C}$ ) for whole-cell, patch-clamp recordings. All electrophysiology recordings were made using Clampex 9.2 and analyzed using Clampfit 10.2 (Molecular Devices). Whole-cell, voltage-clamp recordings of AMPA receptor-mediated spontaneous excitatory postsynaptic currents (sEPSCs) were made at $-70 \mathrm{mV}$ and pharmacologically isolated by the addition of $25 \mu \mathrm{M}$ picrotoxin to the artificial cerebrospinal fluid (ACSF) containing (in mM): 124 $\mathrm{NaCl}, 4.4 \mathrm{KCl}, 2 \mathrm{CaCl}_{2}, 1.2 \mathrm{MgSO}_{4}, 1 \mathrm{NaH}_{2} \mathrm{PO}_{4}, 10$ glucose, and 26 $\mathrm{NaHCO}_{3}$. Cells were allowed to equilibrate to whole-cell configuration for 3-5 min before recordings began. sEPSC recordings were acquired and analyzed in 2 min gap-free blocks. Cells in which the frequency was below $0.2 \mathrm{~Hz}$ were not included in the data analysis. Access resistance was monitored between blocks of sEPSC recordings. Those experiments in which the access resistance changed by $>20 \%$ were not included in the data analyses. Recording electrodes for voltage-clamp experiments were filled with (in mM): $118 \mathrm{CsOH}, 117$ D-gluconic acid, $5 \mathrm{NaCl}, 10 \mathrm{HEPES}$, 0.4 EGTA, $2 \mathrm{MgCl}_{2}$, 5 tetraethylammonium chloride, 4 ATP, 0.3 GTP, $\mathrm{pH} 7.2-7.3,280-290 \mathrm{mOsmol}$. For experiments in which the effects of antagonists were determined, the antagonist was pre-applied for at least $12 \mathrm{~min}$ before application of a test drug and then remained onboard for the duration of the experiment. Whole-cell, current-clamp recordings were performed without the addition of picrotoxin to the ACSF and were carried out at each neuron's resting membrane potential after allowing at least $3 \mathrm{~min}$ for the cell to equilibrate and for the resting membrane potential to stabilize. Recording electrodes for current-clamp experiments were filled with (in mM): $135 \mathrm{~K}^{+}$-gluconate, $5 \mathrm{NaCl}, 2 \mathrm{MgCl}_{2}, 10$ HEPES, 0.6 EGTA, 4 ATP, 0.4 GTP, pH 7.2-7.3, 280-290 mOsmol. Current-clamp experiments analyzing the effect of drugs on resting membrane potential were recorded continuously in gap-free mode for the duration of the experiment.

\section{Statistical analyses}

Statistical analyses were performed using Microsoft Excel 2010 and GraphPad Prism 5, while figures were finalized in CorelDRAW 12. Specifically, when determining whether a compound had a significant effect, a Student's paired $t$ test was used, comparing the baseline value to the experimental value. To compare the effects of different concentrations of drugs on sEPSCs, a one-way ANOVA was used followed by Tukey's post-test to determine the significance of specific comparisons. All values given for drug effects throughout the study are presented as average \pm SEM.

\section{Drugs}

Isoproterenol, CRF, and NBI27914 were purchased from Tocris Bioscience. All other compounds and experimental drugs were purchased from Sigma-Aldrich unless otherwise noted in the text. All experimental drugs were bath applied at their final concentrations as noted in the text. Dimethylsulfoxide (DMSO) was the solvent used for stock solutions of NBI27914 and picrotoxin where the maximum final concentration of DMSO in ACSF was $0.02 \%$ by volume.

\section{Reagents}

Primary antibodies used included rabbit polyclonal anti-Fluorogold antibody (used at 1:3000 dilution) and mouse monoclonal anti-neuronal nuclei antibody (NeuN, used at 1:1000 dilution), both from Millipore Bioscience Research Reagents. Secondary antibodies were purchased from Jackson ImmunoResearch Laboratories and included Cy2conjugated donkey anti-mouse (1:400), Dylight 649-conjugated donkey anti-rabbit (1:1000), and Cy3-conjugated donkey anti-rabbit (1:1000) Fab fragments.

\section{Results}

\section{Electrophysiological properties of CRF neurons in the extended amygdala}

Figure 1 shows the pattern of tomato expression in selected brain regions. Tomato expression was most dense in regions known to have a high density of CRF-producing neurons like the PVN, BNST, and CeA (Fig. $1 A-C$, green cells), while brain regions such as the cortex or striatum, known to have very limited number of CRF-producing neurons, had very sparse expression of tomato. We next assessed the basal properties of the CRF-tomato neurons in the BNST by using current-clamp recordings. Initial analysis revealed a wide range of basal resting membrane potentials. In 23 cells tested, resting membrane potentials of BNST CRF neurons ranged from -71 to $-43 \mathrm{mV}$ (Fig. $1 F$ ).

Previous reports indicate that neurons in the rat and mouse BNST can be categorized into at least three distinct neuronal subtypes based on voltage responses to transient current steps (Egli and Winder, 2003; Hammack et al., 2007). We therefore assessed whether CRF neurons in the mouse BNST could be categorized into similar neuronal subtypes ( $n=13$ mice). Voltage responses were assessed in response to incremental current steps (ranging from $-120 \mathrm{pA}$ to $+120 \mathrm{pA}$ ) of $1500 \mathrm{~ms}$ in duration (Table 1). Using the categorization strategy of Hammack et al. (2007), 10 of 23 neurons tested in this manner fit into previously described categories (I-III) of rat BNST neurons (for examples, Fig. $1 D$ ). The remaining 13 neurons could not be placed into any of the predefined group based on their voltage responses (for examples, Fig. $1 E$ ). For example, these cells did not have a "hyperpolarizing sag" like that seen in type I and type II neurons. In addition, they had a significantly shorter latency to firing first action potentials in response to a suprathreshold current injection compared to type III neurons (see Table 1 for values; $t_{(12)}=$ 5.628, $p<0.0001)$. Ten of these thirteen cells fired only one action potential per depolarizing current injection even in response to the largest current injections tested $(+120 \mathrm{pA})$. The remaining three cells did have multiple action potentials at very positive current injection levels after firing only once at lower current levels (Fig. 1E). In addition, 6 of 13 of these neurons had a transient depolarizing rebound action potential upon termination of the hyperpolarizing current injection (data not shown). Subsequent analysis revealed that CRF neurons with a rebound action potential rested at significantly more depolarized membrane potentials than non-rebounders (rebound vs non-rebound: $-54.8 \pm 2.4 \mathrm{mV}$ vs $-66.3 \pm 1.7 \mathrm{mV}, t_{(11)}=3.988, p<$ $0.005)$. Interestingly, all neurons that had this rebound action potential upon termination of hyperpolarizing current injections fired only one action potential in response to suprathreshold current injections.

For comparison, we performed the same analysis on CRFtomato neurons from the CeA of the same mice tested above. Analysis revealed that CeA CRF neurons are significantly different that BNST CRF neurons in many of their basal properties (Table 1). Resting membrane potentials for CeA CRF neurons were significantly more hyperpolarized than the averaged resting 


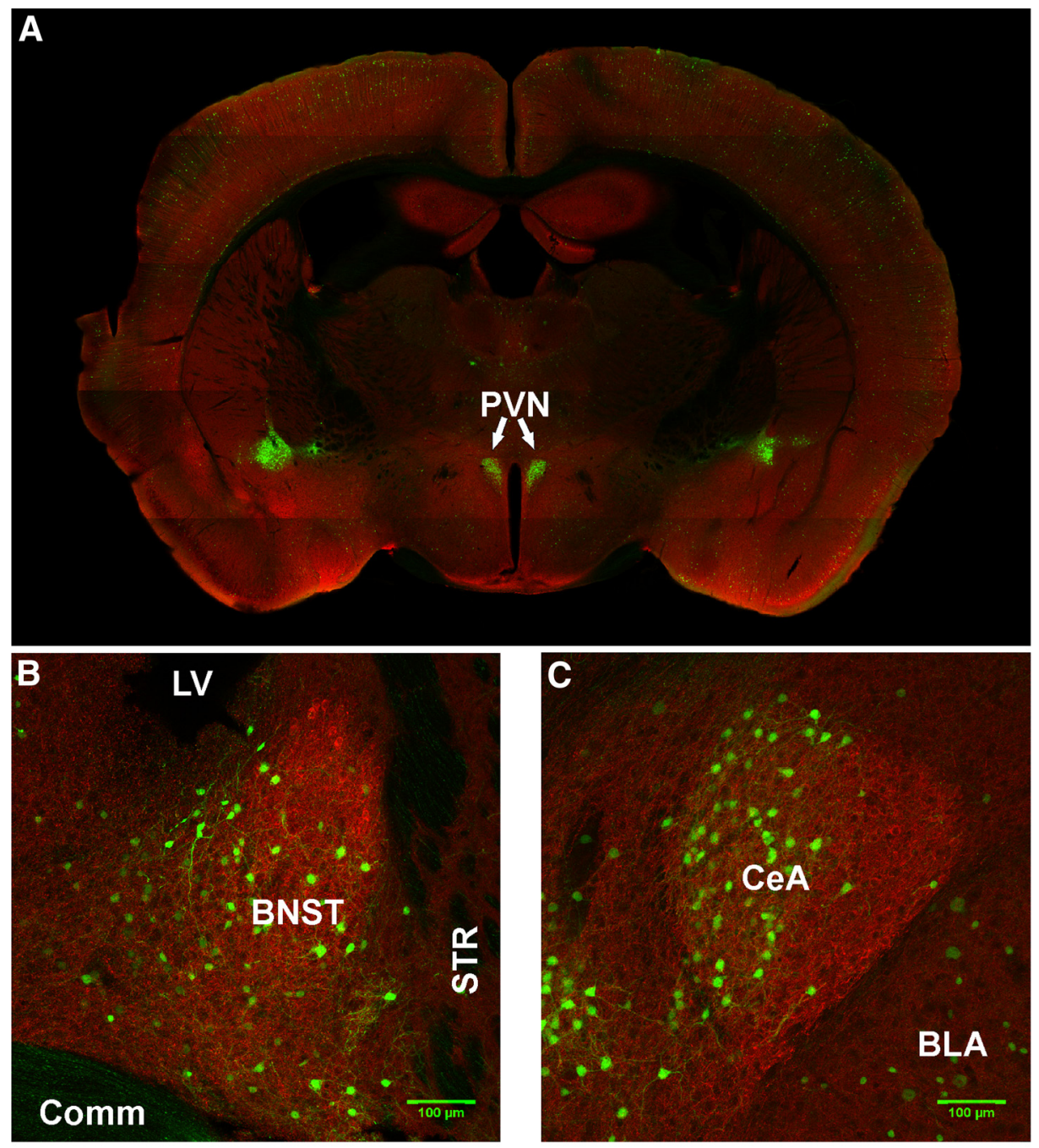

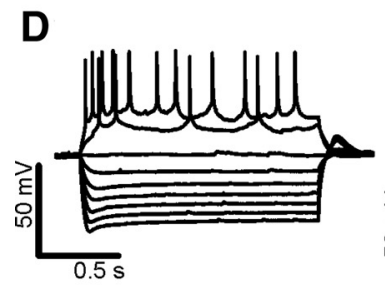

BNST Type I

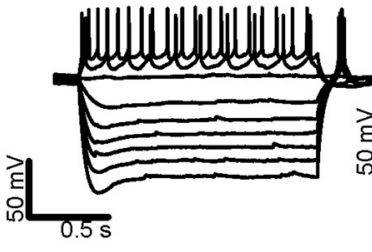

BNST Type II

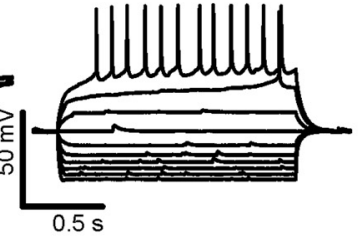

BNST Type III
$\mathbf{E}$

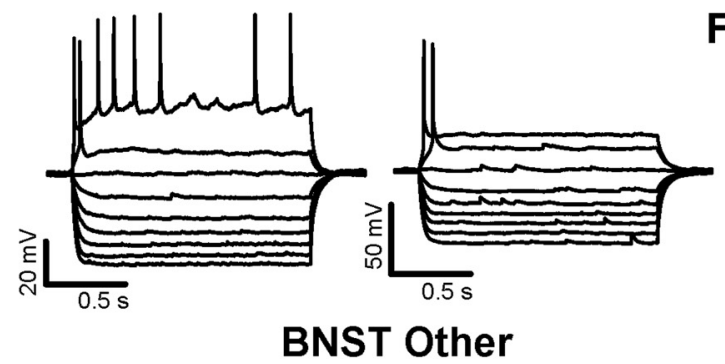

$\mathbf{F}$

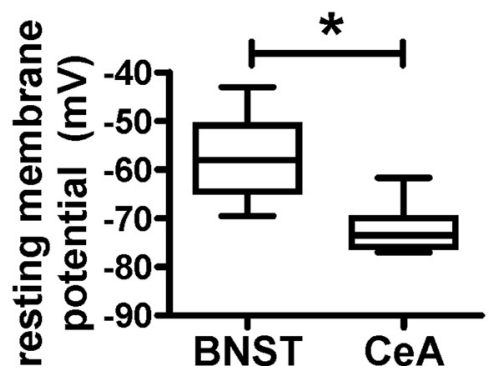

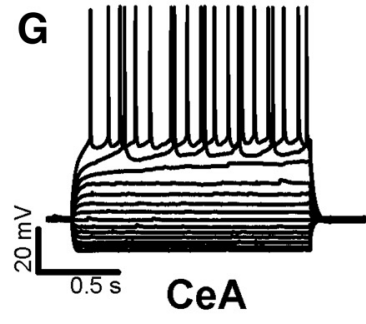

Figure 1. Anatomy and electrophysiologic properties of CRF-tomato neurons. $\boldsymbol{A}-\boldsymbol{C}$, Expression pattern of CRF neurons in the PVN $(\boldsymbol{A})$, BNST $(\boldsymbol{B})$, and (eA $(\boldsymbol{C})$. CRF neurons are false colored in green. MAP2 antibody was used as a background label for neurons and false colored in red. $\boldsymbol{D}, \boldsymbol{E}$, Example traces of membrane voltage responses to positive and negative current injections in BNST CRF neurons. Type I-III neuron classification was based on Hammack and Rainnie (2007). "Other" neurons were BNST CRF neurons that did not fit into previously described cell types. $\boldsymbol{F}$, Group analysis comparing the average resting membrane potential of (RF neurons in the BNST ( $n=17$ neurons) and CeA ( $n=12$ neurons) from eight CRF-tomato mice. Asterisk $\left({ }^{*}\right)$ indicates significant difference between BNST and CeA CRF neurons, $p<0.05$. G, Example trace of membrane voltage responses to current injections in a typical CeA CRF neuron. 
Table 1. Electrophysiologic properties of BNST and CeA CRF-tomato neurons

\begin{tabular}{|c|c|c|c|c|c|}
\hline & \multicolumn{4}{|l|}{ BNST } & \multirow[b]{2}{*}{ CeA } \\
\hline & Type $^{a}$ & Type II $^{a}$ & Type III ${ }^{a}$ & Other & \\
\hline Number $(n)$ & 2 & 4 & 4 & 13 & 12 \\
\hline $\begin{array}{l}R_{m}(M \Omega) \\
\text { Spike }\end{array}$ & $614.0 \pm 117.9$ & $450.6 \pm 56.9$ & $204.9 \pm 30.2$ & $596.3 \pm 111.0$ & $101.4 \pm 9.4^{b}$ \\
\hline Activation threshold (mV) & $-36.6 \pm 0.5$ & $-32.5 \pm 1.2$ & $-30.3 \pm 3.6$ & $-45.6 \pm 2.2^{c, e}$ & $-36.9 \pm 0.9$ \\
\hline Amplitude (mV) & $72.3 \pm 9.1$ & $55.0 \pm 4.9$ & $82.1 \pm 4.3$ & $71.4 \pm 3.9$ & $104.3 \pm 3.6^{b}$ \\
\hline Half-width (ms) & $2.8 \pm 0.4$ & $2.1 \pm 0.09$ & $2.0 \pm 0.4$ & $2.1 \pm 0.3$ & $2.8 \pm 0.0 .2$ \\
\hline Latency (ms) & $183.9 \pm 14.9$ & $83.53 \pm 3.6$ & $857.9 \pm 230.5^{d}$ & $84.0 \pm 5.9$ & $679.3 \pm 114.5^{b}$ \\
\hline
\end{tabular}

All BNST CRF-tomato neurons were grouped for comparison to CeA CRF-tomato neurons.

${ }^{a}$ Neuronal Types as described by Hammock et al., 2007.

${ }^{b}$ Significant difference between CeA and BNST neurons.

"Significant difference between BNST Type III and "other" neurons.

${ }^{d}$ Significant difference between BNST Type III and all BNST types.

${ }^{e}$ Significant difference from BNST Type II neurons.

membrane potential of all BNST CRF neurons $(-72.5 \pm 1.2 \mathrm{mV}$ vs $-59.8 \pm 2.2 \mathrm{mV}$, respectively; $t_{(27)}=6.368, p<0.0001$; Fig. $1 F)$. However CeA CRF neurons may be more similar in nature to type III BNST CRF neurons as they both have longer latency to fire compared to any other group (ANOVA, $F_{(2,30)}=5.525, p<$ 0.01 ), but post hoc analysis revealed that these two cell types do not have significantly different latencies from each other (Tukey's multiple-comparison test, $q=1.09, p>0.05)$. Moreover, CeA CRF neurons seemed to also have more homogeneous voltage responses to current injections, as hyperpolarizing currents caused inwardly rectifying voltage responses in all CeA CRF neurons. In addition, these neurons were either regularly firing or burst firing in response to suprathreshold-positive current injections (Fig. 1G).

\section{Dopamine and isoproterenol depolarize CRF neurons in the BNST}

Our previous reports indicate that $\mathrm{DA}$ and the $\beta$-AR agonist isoproterenol (ISO) can enhance glutamatergic transmission in the BNST via a CRF-dependent mechanism (Kash et al., 2008b; Nobis et al., 2011). In exploring the mechanisms underlying these actions, we found that the effect of DA was activity dependent, and that DA depolarized a subpopulation of BNST neurons of unknown type (Kash et al., 2008a). This led us to hypothesize that DA and ISO may produce CRF-dependent increases in excitatory transmission in the BNST by depolarizing CRF interneurons. Therefore, we next assessed whether DA and ISO depolarize BNST CRF-tomato neurons. Following a $5 \mathrm{~min}$ baseline period in which tomato ${ }^{+}$neurons were monitored at their resting membrane potentials, $3 \mu \mathrm{M}$ ISO or $1 \mu \mathrm{M}$ DA was bath applied (Fig. $2 A$ ). The concentrations of DA and ISO used in this study were previously shown to enhance sEPSC frequency in a CRFR1dependent manner in the BNST (Nobis et al., 2011).

A $6 \mathrm{~min}$ bath application of DA significantly depolarized BNST CRF neurons (a change of $+3.4 \pm 0.6 \mathrm{mV}$ compared to baseline, $t_{(7)}=6.144, n=8, p<0.001$; Fig. $2 B$ ). The level of DA-induced depolarization of BNST CRF neurons was not significantly correlated with their initial basal resting membrane potential $\left(R^{2}=0.014 ; p>0.05\right.$; Fig. $\left.2 C\right)$. The peak effect of DA occurred within 2-5 min post-DA removal, and this effect continued to be significant throughout the duration of the recording (change in membrane potential 15-18 min following the removal of DA: $+2.5 \pm 1.0 \mathrm{mV}$ compared to baseline, $t_{(7)}=2.528, p<$ 0.05 ; Fig. $2 B$ ). A paired $t$ test revealed no significant difference in the level of DA-induced depolarization at peak or at the end of the recording (2-5 $\mathrm{min}$ post-DA vs $15-18 \mathrm{~min}$ post-DA, $t_{(7)}=1.756$, $p=0.12)$.

A 10 min bath application of ISO also significantly changed the resting membrane potentials of BNST CRF neurons to a more depolarized level (a change of $+4.5 \pm 1.4 \mathrm{mV}$ compared to baseline, $t_{(11)}=3.262, n=12, p<0.01$; Fig. $2 B$ ). This depolarization effect peaked at $2-5 \mathrm{~min}$ after the removal of ISO, and the level of ISO depolarization also did not significantly correlate with basal resting membrane potential $\left(R^{2}=0.03, p>0.05\right.$; Fig. $\left.2 D\right)$. However, in a subset of cells tested, the level of ISO-induced depolarization was significantly correlated with an increase in input resistance $\left(R^{2}=0.8, p<0.05\right.$, Fig. $\left.2 E\right)$. The effect of ISO was long lasting, as a paired $t$ test revealed no significant difference in the level of ISO-induced depolarization at peak or at the end of the recording $\left(t_{(11)}=1.601, p>0.14\right)$.

\section{Microsphere labeling of BNST projection neurons}

The above data suggest that catecholamines enhance BNST CRF neuron activity, potentially leading to increased excitability of BNST projection neurons. It is unclear whether different populations of BNST neurons project to specific targets or whether a single population of BNST neurons might simultaneously project to multiple brain regions. For this reason, we microinjected spectrally distinct retrograde tracers into two important target regions of the BNST, the hypothalamus and the VTA, and tested for colocalization of these tracers in the BNST with confocal microscopy. Medial aspects of the hypothalamus were targeted as this area contains the paraventricular nucleus, and projections from the BNST to this brain region are thought to be important in stress-related behaviors (Jankord and Herman, 2008; Radley and Sawchenko, 2011). The VTA was chosen for its role in drugseeking behavior (You et al., 2007) and the potential importance of BNST projections to the VTA in reinstatement (Briand et al., 2010). The BNST slices used for confocal microscopy were at the same level used in other portions of this study for electrophysiology. Fluorogold was microinjected into the hypothalamus, and red/infra-red fluorescent latex microbeads were injected into the ipsilateral VTA (for examples of injection sites, Fig. 3C,D). NeuN was used as a pan-neuronal marker in BNST slices to ensure 


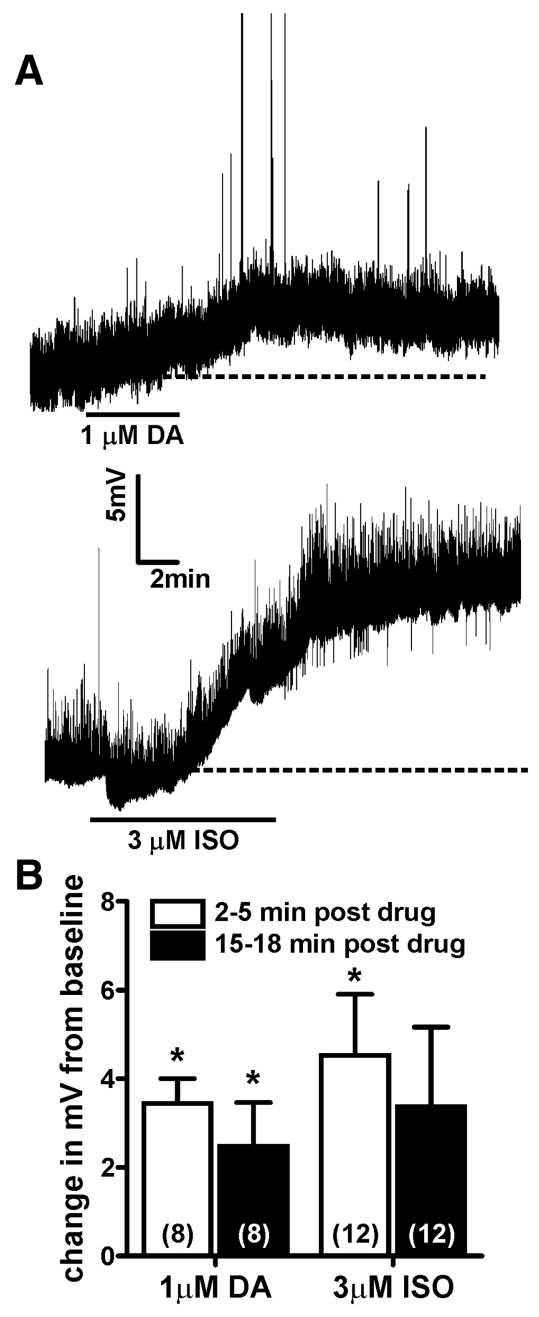

C
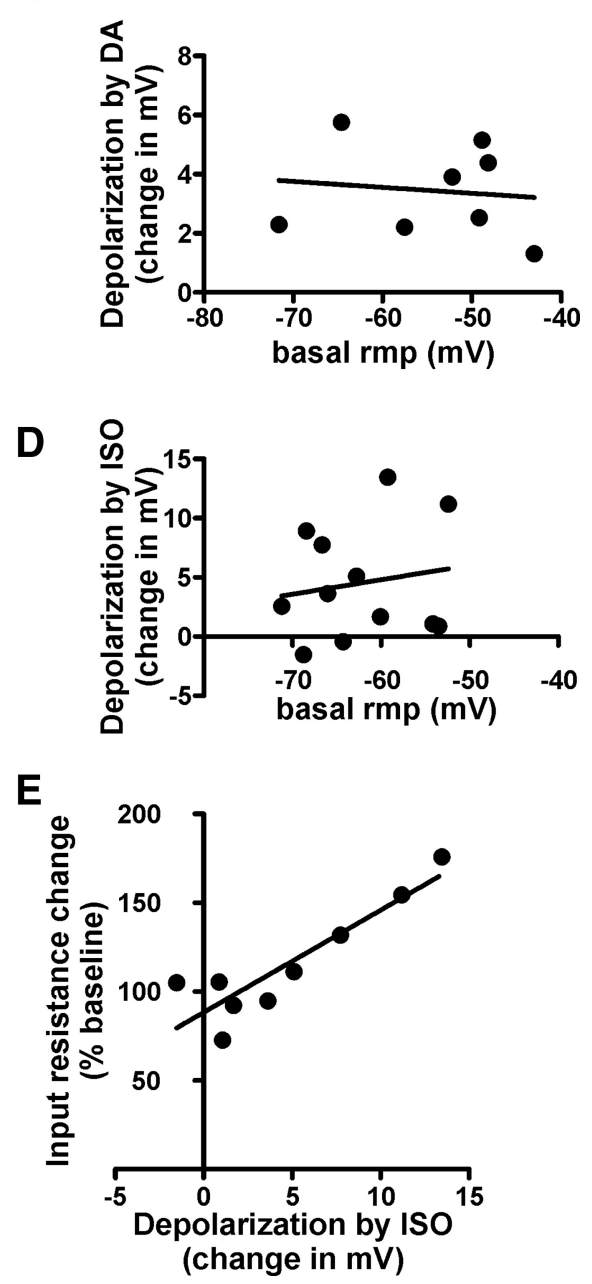

Figure 2. Dopamine and $\beta$-adrenergic receptor activation depolarizes BNST CRF neurons. $\boldsymbol{A}$, Example traces showing the time course of dopamine or the $\beta$-adrenergic receptor agonist isoproterenol induced depolarization of BNST CRF neurons. Dashed lines indicate basal resting membrane potential of the neuron being recorded. $\boldsymbol{B}$, Bar graph summarizing the averaged depolarizing effect of DA and ISO on BNST CRF neurons at peak (2-5 min post-drug removal) and at extended time points (15-18 min post-drug removal). Asterisk $\left(^{*}\right)$ indicates significant difference from basal resting membrane potential. Numbers in parenthesis indicates number of neurons per group taken from 8 CRF-tomato mice. C, D, Analysis showing that basal resting membrane potential ( $\mathrm{rmp}$ ) of BNST CRF neurons did not correlate to the magnitude of either DA-induced ( $\boldsymbol{C}$ or ISO-induced $(\boldsymbol{D})$ depolarization. $\boldsymbol{E}$, Analysis showing that the magnitude of ISO-induced depolarization was significantly correlated with increases in input resistance $\left(R^{2}=\right.$ $0.8, p<0.05)$.

that retrograde tracers were specifically filling neurons (Fig. $3 A$ ). Colocalization analysis revealed that only $\sim 1 \%$ of VTAprojecting neurons also colabeled as projecting to the hypothalamus, and $\sim 5 \%$ of hypothalamus neurons also colabeled as projecting to the VTA (Table 2). Overall, these findings suggest that BNST neurons projecting to the VTA may be largely distinct from BNST neurons projecting to the medial aspects of the hypothalamus.

\section{Electrophysiological properties of \\ VTA-projecting BNST neurons}

Since the VTA plays a well characterized role in drug-seeking behaviors and since BNST neurons that project to the VTA have been proposed to become active during reinstatement (Briand et al., 2010), we chose to focus our electrophysiological analysis on VTA-projecting BNST neurons. Previous reports suggest that the electrophysiological properties of projection neurons in the rat

BNST can be distinct from BNST interneurons (Dumont and Williams, 2004; Kash et al., 2008a), suggesting that VTAprojecting BNST neurons could potentially all be classified into one of the previously described subtypes (Hammack et al., 2007). In eight cells tested from five animals using current-clamp recording conditions similar to those in Figure 2, we found evidence of three different types of VTA-projecting BNST neurons; two neurons were similar to type I neurons, two were similar to type II neurons, and four neurons were similar to "other" neurons characterized above (see Fig. $3 B$ and Table 3). Interestingly, in this limited sample we did not find any VTA-projecting BNST neurons to be classified as type III neurons.

\section{CRF enhances sEPSC frequency on VTA-projecting BNST neurons} Since DA and ISO were able to significantly depolarize BNST CRF neurons, we next wanted to determine how enhanced CRF levels might alter the activity of VTA-projecting BNST neurons. We performed whole-cell voltage-clamp recordings in these neurons and determined the effect of exogenously applied CRF on sEPSCs. Bath application of CRF (10 nM-1 $\mu \mathrm{M}, n=3-6$ cells per concentration) enhanced sEPSC frequency in a concentration-dependent manner (ANOVA, $F_{(3,14)}=9.329, p<$ 0.005; Fig. $4 A, B)$, suggesting that $\mathrm{CRF}$ enhances presynaptic glutamatergic release onto VTA-projecting BNST neurons. There were no significant effects of CRF on sEPSC amplitude at any concentration tested $\left(F_{(3,14)}=1.972, p=\right.$ 0.16 , Fig. $4 C$ ). In addition, there were no significant effects of CRF on sEPSC area, rise time, decay time, holding current, or membrane resistance at any concentration tested (data not shown). To determine which CRF receptor subtype was mediating this effect, we pretreated a separate group of slices with the CRFR1 selective antagonist NBI27914 (NBI, 1 $\mu \mathrm{M})$. While NBI had no significant effect on its own on basal sEPSC frequency compared to control slices [control $(n=18)$ vs NBI $(n=6): 1.8 \pm 0.5$ vs $3.1 \pm 0.7(\mathrm{~Hz}) ; t_{(22)}=1.429, p=$ 0.17 , pretreatment with NBI significantly blocked the ability of $300 \mathrm{~nm}$ CRF to enhance sEPSC frequency [300 nM CRF vs $\mathrm{NBI}+300 \mathrm{nMCRF}(n=5$ per group $): 139.5 \pm 13.0 \mathrm{vs} 100.0 \pm$ $9.8 \%$ (expressed as percent of baseline), $t_{(8)}=2.426, p<0.05$; Figure $4 D$ ], suggesting that CRF-mediated enhancement of sEPSC frequency in VTA-projecting BNST neurons involves activation of CRFR1.

Chronic intermittent ethanol enhances basal glutamatergic tone in the BNST and occludes the effect of exogenous CRF We next sought to determine how exposure and withdrawal from chronic ethanol might alter the ability of CRF to modulate glu- 
tamate release onto VTA-projecting BNST neurons. Tracer-injected mice received 2 weeks of chronic intermittent ethanol vapor chamber exposure as described previously (Wills et al., 2012). This regimen has previously been demonstrated to enhance alcohol-seeking behavior (Becker and Lopez, 2004; Griffin et al., 2009). On the last day of CIE exposure, mice were allowed to go through $4-5 \mathrm{~h}$ of withdrawal before slicing. Sham mice received the same treatment design, except they never received ethanol. Since repeated transferring of sham mice between the colony room and the vapor chamber room as well as the daily injections of pyrazole could be a stressor, we first sought to confirm that sham mice were not different from their naive counterparts. We recorded from VTAprojecting BNST neurons and found that basal sEPSC frequency was not significantly different in sham mice versus naive mice $(1.8 \pm 0.4 \mathrm{vs} 1.8 \pm 0.5 \mathrm{~Hz}$, $n=7$ and 18 respectively, $t_{(23)}=0.035$, $p=0.97$; Fig. $5 A$ ). In addition, $300 \mathrm{~nm}$ CRF significantly enhanced sEPSC frequency in sham mice in a similar manner as naive mice $[161.3 \pm 15.6 \%$ vs $139.5 \pm 13.0 \%$, respectively (percent of baseline); $n=5$ /group; CRF effect in sham mice compared to baseline, $t_{(4)}=$ 3.89, $p<0.05$; CRF effects in sham vs naive mice, $t_{(8)}=1.066, p=0.32$ ]. Therefore, we decided to group sham and naive mice for comparison to CIE mice. Basal sEPSC frequency was enhanced in VTA-projecting BNST neurons from CIE mice compared to sham/naive mice (3.4 \pm 0.6 vs $1.8 \pm 0.4 \mathrm{~Hz}, n=12$ and 25 respectively, $t_{(35)}=2.385, p<$ 0.05 ; Fig. $5 B$ ), suggesting that glutamatergic tone onto VTAprojecting BNST neurons is enhanced in CIE mice during acute withdrawal time points. CIE did not cause any significant changes to basal sEPSC amplitude compared to naive or sham groups (ANOVA, $\left.F_{(2,35)}=1.948, p=0.16\right)$. Furthermore, from this enhanced level of glutamatergic tone, $300 \mathrm{nM}$ CRF no longer could significantly alter sEPSC frequency in VTA-projecting BNST neurons [300 nM CRF-induced change $83.8 \pm 7.3 \%$ (percent of baseline, $n=5)$; $300 \mathrm{~nm} \mathrm{CRF} \mathrm{effect} \mathrm{in} \mathrm{CIE} \mathrm{group} \mathrm{compared} \mathrm{to} \mathrm{baseline,} t_{(4)}=$ 2.223, $p=0.09$; effect of $300 \mathrm{nM}$ CRF in CIE compared to sham/ naive, $t_{(13)}=4.258, p<0.001$; Figure $5 C$ ], suggesting that CIE may modulate BNST CRF signaling in vivo. To test the hypothesis that CIE-induced changes to basal sEPSC frequency in VTA-projecting BNST neurons occur through a CRFR1-dependent mechanism, tracer-injected mice were treated with daily injections of NBI before CIE or sham exposures (Fig. 5D,E). Daily NBI injections did not significantly alter basal sEPSC frequency in VTA-projecting BNST neurons in sham $+\mathrm{NBI}$ animals compared to the previous naive/ sham group (sham + NBI vs naive/sham: $2.2 \pm 0.3$ vs $1.8 \pm 0.4, n=$ 6 and 26 respectively, $t_{(29)}=0.4827, p=0.63$ ). Importantly, in mice treated with NBI before CIE exposure, CIE did not cause a significant increase in basal sEPSC frequency in VTA-projecting BNST neurons compared to sham $+\mathrm{NBI}(\mathrm{CIE}+\mathrm{NBI}$ vs sham $+\mathrm{NBI}: 2.0 \pm 0.7 \mathrm{vs}$ $2.2 \pm 0.3, n=6$ /group, $\left.t_{(10)}=0.2147, p=0.83\right)$. Together, these findings suggest that CIE modulates in vivo CRF activity in the BNST
Table 2. Retrograde Tracer co-labeling in the BNST

\begin{tabular}{lllc}
\hline Mouse no. & VTA projecting & $\begin{array}{l}\text { Number of cells } \\
\text { Hypothalamus projecting }\end{array}$ & Colabeled cells \\
\hline 1 & 312 & 77 & 3 \\
2 & 241 & 44 & 4 \\
3 & 172 & 28 & 0 \\
4 & 118 & 38 & 2 \\
5 & 195 & 23 & 2 \\
Total (\% colabeled) & $1038(1.1 \%)$ & $210(5.2 \%)$ & 11
\end{tabular}

Table 3. Electrophysiologic Properties of VTA-projecting BNST neurons

\begin{tabular}{|c|c|c|c|c|}
\hline & Type I $^{a}$ & $\begin{array}{l}\text { BNST } \\
\text { Type } \|^{a}\end{array}$ & Type III ${ }^{a}$ & Other \\
\hline Number $(n)$ & 2 & 2 & 0 & 4 \\
\hline $\begin{array}{l}\text { Resting membrane } \\
\text { potential }(\mathrm{mV})\end{array}$ & $-56.8 \pm 1.3$ & $-53.5 \pm 2.5$ & $n / a$ & $-69.6 \pm 6.3$ \\
\hline $\begin{array}{l}R_{\mathrm{m}}(\mathrm{M} \Omega) \\
\text { Spike }\end{array}$ & $628.0 \pm 112.2$ & $348.5 \pm 17.6$ & n/a & $526.6 \pm 58.3$ \\
\hline $\begin{array}{l}\text { Activation threshold } \\
(\mathrm{mV})\end{array}$ & $-38.7 \pm 0.05$ & $-36.71 \pm 2.2$ & $n / a$ & $-43.7 \pm 3.2$ \\
\hline Amplitude (mV) & $77.7 \pm 8.3$ & $69.31 \pm 8.1$ & n/a & $76.7 \pm 7.1$ \\
\hline Rise time (ms) & $0.95 \pm 0.083$ & $1.2 \pm 0.2$ & $\mathrm{n} / \mathrm{a}$ & $1.1 \pm 0.2$ \\
\hline Decay time (ms) & $3.3 \pm 0.081$ & $4.6 \pm 0.1$ & $\mathrm{n} / \mathrm{a}$ & $3.3 \pm 0.5$ \\
\hline Half-width (ms) & $2.1 \pm 0.085$ & $2.3 \pm 0.09$ & $n / a$ & $1.9 \pm 0.06$ \\
\hline Latency (ms) & $448.7 \pm 254.5$ & $193.3 \pm 31.1$ & $\mathrm{n} / \mathrm{a}$ & $122.4 \pm 15.2$ \\
\hline
\end{tabular}

${ }^{a}$ Neuronal types as described by Hammock et al. (2007). 
A

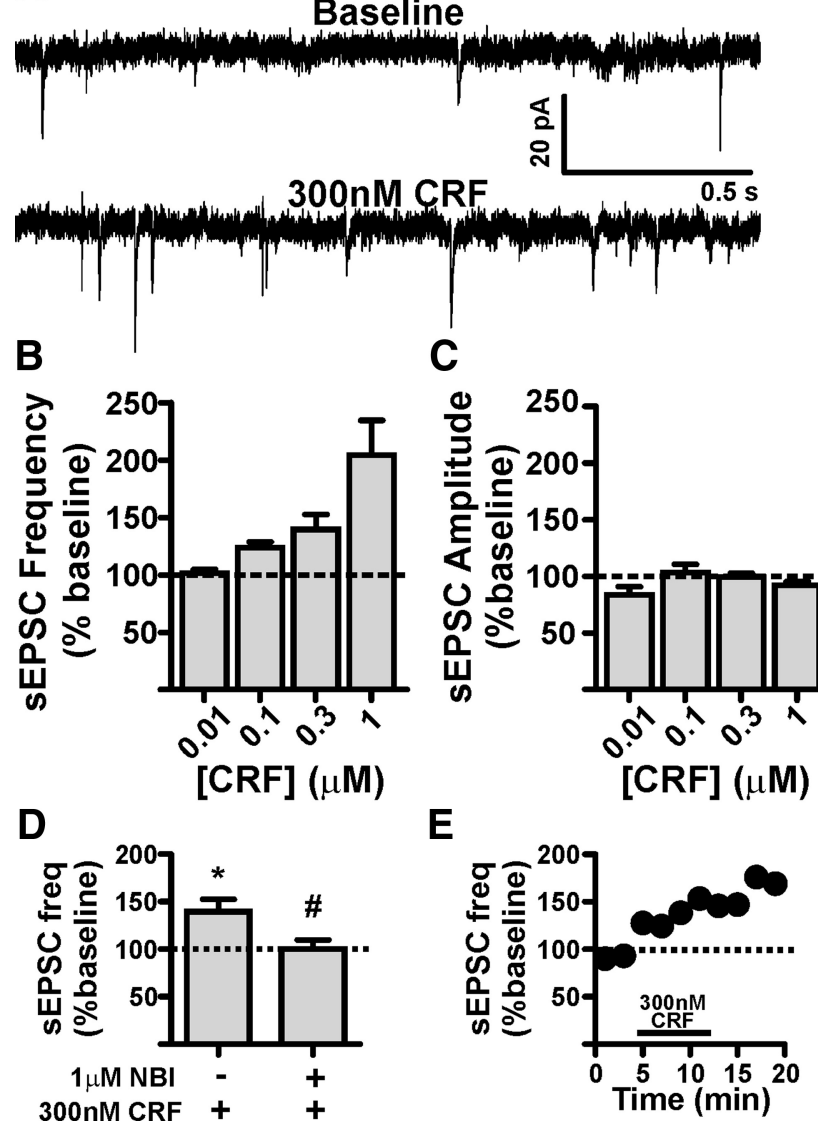

A Naive/Sham

Baseline

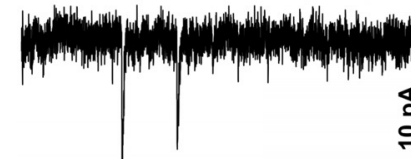

300nM CRF

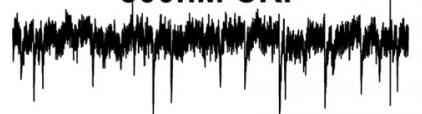

B

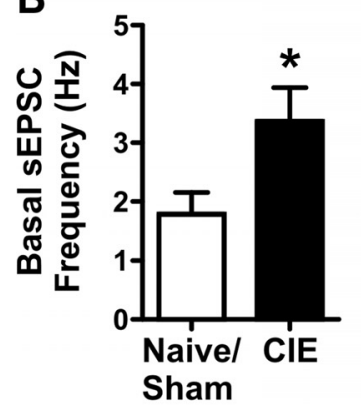

D

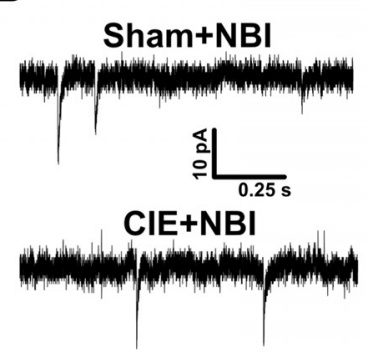

CIE

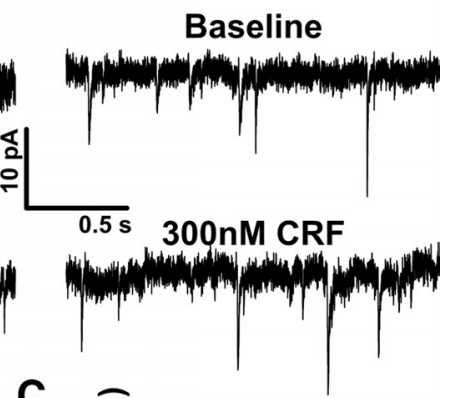

C

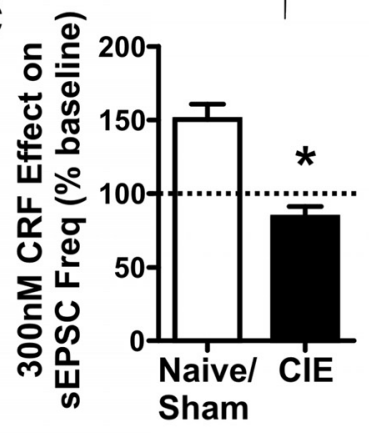

$\mathbf{E}$

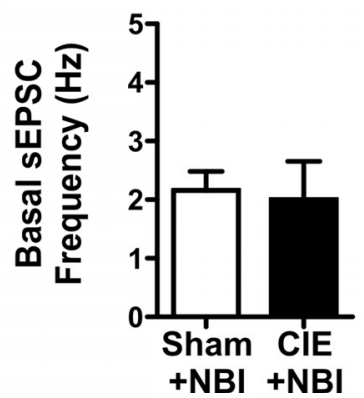

Figure 4. CRF enhances presynaptic glutamatergic transmission onto VTA-projecting BNST neurons. $A$, Example traces of sEPSCS recorded from a VTA-projecting BNST neuron during baseline and after application of $300 \mathrm{~nm}$ CRF. $\boldsymbol{B}$, Bar graph showing that CRF significantly enhances sEPSC frequency in VTA-projecting BNST neurons in a concentration-dependent manner; $n=3-6$ cells per group taken from 13 mice $C$, Bar graph summarizing the lack of effect of CRF on sEPSC amplitude in VTA-projecting BNST neurons. D, Bar graph summarizing that pretreatment with a selective CRFR1 antagonist NBI 27914 can significantly reduce the potentiating effect of $300 \mathrm{~nm}$ CRF on sEPSC frequency; $n=5$ neurons from four mice for CRF group; $n=$ 5 neurons from three mice for $\mathrm{NBI}+$ CRF group; asterisk $\left({ }^{*}\right)$ indicates significant difference from baseline, $p<0.05$; pound sign (\#) indicates significant difference between groups, $p<$ 0.05 . $\boldsymbol{E}$, Time course of $300 \mathrm{~nm}$ CRF-induced enhancement of SEPSC in the cell shown in $\boldsymbol{A}$. Dotted lines in $\boldsymbol{B}-\boldsymbol{E}$ indicate normalized basal sEPSC frequency.

through a CRFR1-dependent mechanism and that during acute withdrawal BNST CRFR1 may be maximally active.

\section{Discussion}

Stress-induced reinstatement is hypothesized to occur via increased BNST excitability, likely through catecholamine and CRF signaling interactions within BNST (Brown et al., 2009; Briand et al., 2010; Buffalari and See, 2011). Here we used a combination of strategies to elucidate a potential mechanism by which catecholamines may influence CRF activity to enhance BNST excitatory neurotransmission, and we show that this system is modulated by chronic ethanol exposure. Our data show that catecholamines can depolarize BNST CRF neurons, potentially leading to increased CRF release. In turn, CRF enhances glutamatergic transmission onto VTA-projecting BNST neurons, suggesting that elevated extracellular CRF in the BNST may modulate neurocircuitry critical to drug-seeking behavior. Importantly, CIE increases basal glutamatergic tone onto VTAprojecting BNST neurons and occludes the effect of CRF. This

Figure 5. Acute withdrawal from chronic intermittent ethanol, $\mathrm{CIE}$, enhances basal glutamatergic tone onto VTA-projecting BNST neurons and occludes the effect of exogenously applied CRF. $A$, Example traces of sEPSCs recorded from VTA-projecting BNST neurons from CIE and sham exposed mice during baseline and after exogenous application of $300 \mathrm{~nm}$ CRF. B, Bar graph comparing the basal sEPSC frequency in sham/naive controls ( $n=26)$ vs CIE ( $n=12)$ from 24 mice. Asterisk $(*)$ indicates significant difference between groups, $p<0.05$. C, Bar graph summarizing the effect of $300 \mathrm{~nm}$ CRF on sEPSC frequency in sham/naive ( $n=11)$ vs CIE ( $n=$ 5) from 13 mice. $\boldsymbol{D}$, Example traces of $s$ EPSCs recorded from VTA-projecting BNST neurons from CIE and sham-exposed mice treated with $60 \mathrm{mg} / \mathrm{kg} \mathrm{NBI} 27914$ before daily vapor chamber exposure. $\boldsymbol{E}$, Bar graph showing no differences in basal sEPSC frequency in sham $+\mathrm{NBI}(n=6)$ vs $\mathrm{CIE}+\mathrm{NBI}(n=6)$ during acute withdrawal time points in 6 mice. Asterisk $(*)$ indicates significant difference between groups, $p<0.05$. Dotted line indicates normalized basal sEPSC frequency.

effect of CIE can be blocked by pretreating EtOH exposed mice with a CRFR1 antagonist, suggesting that CIE modulates BNST CRF neurocircuitry in vivo and that this neurocircuit can become hyperactive during withdrawal. Together, these findings suggest the BNST contains an ethanol-sensitive circuit wherein elevated catecholamines increase CRF neuron activity to enhance excitatory transmission onto BNST neurons projecting to the VTA (Fig. 6, summary model).

Electrophysiological properties of BNST neurons

Previous reports indicate that BNST neurons may be classified into distinct subtypes based on electrophysiologic properties. In the rat BNST, three different classes of neurons have been described based on membrane voltage responses to current injections (Hammack et al., 2007). In addition, BNST projection 
neurons in the rat may be distinguished from local interneurons based on the presence of Ih currents (Dumont and Williams, 2004). Therefore, it could be hypothesized that BNST neurons classified by protein content or terminal projections may have homogenous electrophysiologic properties, information that could then be used to identify specific BNST neuronal subpopulations without needing prior genetic or surgical manipulations. However, the data presented here suggest that this may not be the case. Our data indicate that there are at least four electrophysiologically separable subtypes of CRF neurons and three types of VTA-projecting neurons in the mouse BNST. The presence of at least four categories of electrophysiologically distinct categories of BNST neurons is more than previously described and could be due to differences in rat and mouse BNST physiology, differences in recording sites within the slice, or differences in recording conditions. However, CeA CRF neurons seem much more homogenous in nature than BNST CRF neurons recorded under similar conditions, suggesting that our recording conditions are not a major factor in BNST neuron subtype variability. Indeed, differences between BNST neuronal subtypes may to some degree be due to one neuronal subtype recorded during different activation states, although evidence does suggest unique mRNA profiles (Hammack et al., 2007). These data point to the use of fluorescent markers based on neuronal protein content or terminal projections as an important approach to study specific BNST neuron subpopulations.

\section{Catecholamine effects on BNST CRF neurons}

We have previously shown that DA and ISO can enhance sEPSC frequency in the BNST in an activity-dependent manner (Kash et al., 2008b; Nobis et al., 2011). This effect can be mimicked by application of CRF and blocked by pretreatment with a CRFR1 antagonist, suggesting that catecholamine effects on BNST excitatory transmission require CRF receptor activation, possibly by increasing CRF release from local sources. To record specifically from CRF neurons in the BNST, we crossed two lines of commercially available mice to create the CRF-tomato line, which expresses a red fluorescent protein specifically in CRF neurons. The expression of red fluorescent protein in these mice is most dense in brain regions that have high levels of CRF-producing neurons, like the PVN, BNST, and CeA. In recordings from these mice, we found that DA and ISO caused significant and prolonged depolarization of BNST CRF neurons. Importantly, the time course of DA and ISO depolarization of CRF neurons is similar to the time course of activity-dependent DAand ISO-induced increases of glutamatergic transmission in the BNST (Kash et al., 2008b; Nobis et al., 2011), suggesting that catecholamine enhancement of BNST excitability may be due to increased CRF release from local BNST neurons.

BNST activity is necessary for reinstatement to drug seeking (Buffalari and See, 2011). Previous findings show that stressmediated increases in extracellular BNST NE (Pacak et al., 1995) may drive reinstatement to drug seeking (Brown et al., 2011) via activation of $\beta$-ARs (Leri et al., 2002), a system that may interact with BNST CRF circuitry (Erb and Stewart, 1999; Funk et al., 2006; Wang et al., 2006) to initiate reinstatement. The data presented here expand on this hypothesis and suggest that catecholamine-CRF neurocircuit interactions in the BNST may be an important locus for initiation of stress-induced reinstatement.

While the role for BNST $\beta$-ARs in reinstatement is well characterized, a potential role of BNST DA in reinstatement is much less clear. Amygdala DA signaling has been shown to be important in cue-induced reinstatement to drug seeking (Berglind et al., 2006), but the role of BNST DA in reinstatement has not yet been tested. However, inactivation of the BNST has been shown to reduce cue-induced reinstatement of cocaine seeking (Buffalari and See, 2011), and rewarding stimuli have been shown to increase extracellular DA in the BNST (Carboni et al., 2000; Park et al., 2012), which would likely increase BNST excitation based on our data. Together, these findings suggest a possible role of BNST DA activity in cue-induced reinstatement. Recent evidence suggests that DA can be released from NE terminals due to amphetamine-induced alterations in NE transporter activity, at least in the hippocampus (Smith and Greene, 2012). NE transporters in the BNST can become upregulated after chronic cocaine self-administration (Macey et al., 2003), suggesting that drug-induced alterations in BNST could also alter extracellular NE and/or DA levels through NE transporters. Our data indicate that DA can depolarize BNST CRF neurons, similar to $\beta$-AR activation. Since NE terminals in the BNST likely become activated during stress (Pacak et al., 1995), these findings suggest DA may also be released in the BNST following stress after drug exposure and further suggest a potential role of BNST DA in stressinduced reinstatement. 


\section{CRF and CIE increase excitatory drive onto BNST neurons projecting to the VTA}

The BNST has widespread projections that can regulate a variety of behaviors, such as stress and reward (Dong et al., 2001; Dong and Swanson, 2004; Dong and Swanson, 2006; Ulrich-Lai and Herman, 2009). However, it is not clear whether distinct populations of BNST neurons project to one specific brain region or whether a single BNST neuron may project to multiple downstream targets simultaneously. Here, we provide initial evidence that BNST neurons projecting to the hypothalamus and VTA, two well characterized BNST targets, likely only partially overlap, suggesting that distinct pools of BNST projections neurons may independently regulate circuitry involved in reward and/or stress behavior.

Supporting this hypothesis, previous reports indicate that reinstatement increases neuronal markers of activation specifically in BNST neurons that project to the VTA (Briand et al., 2010). The data presented here are in agreement with these previous findings and suggest that CRF may be an important modulator of excitatory drive onto VTA-projecting BNST neurons. We find that acute withdrawal from CIE can enhance basal glutamatergic tone onto VTA-projecting BNST neurons but occlude the effect of exogenous CRF. Additionally, the CIE enhancement of basal glutamatergic tone is blocked by pretreatment with a CRFR1 antagonist. These data are in agreement with previous work indicating that extracellular CRF is elevated during ethanol withdrawal (Olive et al., 2002) and suggest that CIE can modulate normal CRF signaling in the BNST in vivo. CIE can increase CRFR1 sensitivity in other components of the extended amygdala after prolonged withdrawal (Roberto et al., 2010), which might suggest that CRFR1 receptors in the BNST may also become sensitized following long-term withdrawal. In conjunction with the hypothesis that catecholamine-CRF interactions in the BNST may be critical for reinstatement, $\mathrm{EtOH}$ withdrawal-induced sensitization CRF circuitry in the BNST could be one mechanism for the long-term challenge of stress-induced relapse in recovering alcoholics (Sinha, 2007).

\section{Summary and conclusions}

Our data indicate a putative two-step reinstatement circuit centered around CRFR1 activity in the BNST, wherein catecholamines can enhance activity of BNST CRF neurons that may in turn increase the excitability of BNST neurons that project to the VTA. While more work will be needed to conclusively show the exact mode of action of this circuitry during reinstatement, we hypothesize that engagement of this circuitry following exposure to drug-associated cues or stressors likely results in increased signaling from the BNST to the VTA, thereby driving drug seeking. While the data presented here focuses on the potential role of the BNST-CRF neurocircuitry in alcoholism, recent work indicates that this neurocircuitry may also be recruited following chronic cocaine (Nobis et al., 2011) or morphine exposure (Wang et al., 2006). Together, these findings suggest that perturbations of BNST CRF signaling may be a common mechanism for relapse regardless of the drug abused. Future research identifying specific targets within this circuitry may improve strategies for more effective long-term treatment of alcohol and drug addiction.

\section{References}

Becker HC, Lopez MF (2004) Increased ethanol drinking after repeated chronic ethanol exposure and withdrawal experience in C57BL/6 mice. Alcohol Clin Exp Res 28:1829-1838. CrossRef Medline
Berglind WJ, Case JM, Parker MP, Fuchs RA, See RE (2006) Dopamine D1 or D2 receptor antagonism within the basolateral amygdala differentially alters the acquisition of cocaine-cue associations necessary for cueinduced reinstatement of cocaine-seeking. Neuroscience 137:699-706. CrossRef Medline

Briand LA, Vassoler FM, Pierce RC, Valentino RJ, Blendy JA (2010) Ventral tegmental afferents in stress-induced reinstatement: the role of cAMP response element-binding protein. J Neurosci 30:16149-16159. CrossRef Medline

Brown ZJ, Tribe E, D'souza NA, Erb S (2009) Interaction between noradrenaline and corticotrophin-releasing factor in the reinstatement of cocaine seeking in the rat. Psychopharmacology (Berl) 203:121-130. CrossRef Medline

Brown ZJ, Nobrega JN, Erb S (2011) Central injections of noradrenaline induce reinstatement of cocaine seeking and increase c-fos mRNA expression in the extended amygdala. Behav Brain Res 217:472-476. CrossRef Medline

Buffalari DM, See RE (2011) Inactivation of the bed nucleus of the stria terminalis in an animal model of relapse: effects on conditioned cueinduced reinstatement and its enhancement by yohimbine. Psychopharmacology 213:19-27. CrossRef Medline

Carboni E, Silvagni A, Rolando MT, Di Chiara G (2000) Stimulation of in vivo dopamine transmission in the bed nucleus of stria terminalis by reinforcing drugs. J Neurosci 20:RC102. Medline

Dong HW, Swanson LW (2004) Organization of axonal projections from the anterolateral area of the bed nuclei of the stria terminalis. J Comp Neurol 468:277-298. CrossRef Medline

Dong HW, Swanson LW (2006) Projections from bed nuclei of the stria terminalis, dorsomedial nucleus: implications for cerebral hemisphere integration of neuroendocrine, autonomic, and drinking responses. J Comp Neurol 494:75-107. CrossRef Medline

Dong HW, Petrovich GD, Watts AG, Swanson LW (2001) Basic organization of projections from the oval and fusiform nuclei of the bed nuclei of the stria terminalis in adult rat brain. J Comp Neurol 436:430-455. CrossRef Medline

Dumont EC, Williams JT (2004) Noradrenaline triggers GABAA inhibition of bed nucleus of the stria terminalis neurons Projecting to the Ventral tegmental Area. J Neurosci 24:8198-8204. CrossRef Medline

Egli RE, Winder DG (2003) Dorsal and ventral distribution of excitable and synaptic properties of neurons of the bed nucleus of the stria terminalis. J Neurophysiol 90:405-414. CrossRef Medline

Egli RE, Kash TL, Choo K, Savchenko V, Matthews RT, Blakely RD, Winder DG (2005) Norepinephrine modulates glutamatergic transmission in the bed nucleus of the stria terminalis. Neuropsychopharmacology 30 : 657-668. CrossRef Medline

Erb S, Stewart J (1999) A role for the bed nucleus of the stria terminalis, but not the amygdala, in the effects of corticotropin-releasing factor on stressinduced reinstatement of cocaine seeking. J Neurosci 19:RC35. Medline

Erb S, Salmaso N, Rodaros D, Stewart J (2001) A role for the CRFcontaining pathway from central nucleus of the amygdala to bed nucleus of the stria terminalis in the stress-induced reinstatement of cocaine seeking in rats. Psychopharmacology (Berl) 158:360-365. CrossRef Medline

Funk D, Li Z, Lê AD (2006) Effects of environmental and pharmacological stressors on c-fos and corticotropin-releasing factor mRNA in rat brain: Relationship to the reinstatement of alcohol seeking. Neuroscience 138: 235-243. CrossRef Medline

Georges F, Aston-Jones G (2001) Potent regulation of midbrain dopamine neurons by the bed nucleus of the stria terminalis. J Neurosci 21:RC160. Medline

Griffin WC III, Lopez MF, Yanke AB, Middaugh LD, Becker HC (2009) Repeated cycles of chronic intermittent ethanol exposure in mice increases voluntary ethanol drinking and ethanol concentrations in the nucleus accumbens. Psychopharmacology (Berl) 201:569-580. CrossRef Medline

Hammack SE, Mania I, Rainnie DG (2007) Differential expression of intrinsic membrane currents in defined cell types of the anterolateral bed nucleus of the stria terminalis. J Neurophysiol 98:638-656. CrossRef Medline

Healey JC, Winder DG, Kash TL (2008) Chronic ethanol exposure leads to divergent control of dopaminergic synapses in distinct target regions. Alcohol 42:179-190. CrossRef Medline 
Jankord R, Herman JP (2008) Limbic regulation of hypothalamo-pituitaryadrenocortical function during acute and chronic stress. Ann N Y Acad Sci 1148:64-73. CrossRef Medline

Kash TL, Matthews RT, Winder DG (2008a) Alcohol inhibits NR2Bcontaining NMDA receptors in the ventral bed nucleus of the stria terminalis. Neuropsychopharmacology 33:1379-1390. CrossRef Medline

Kash TL, Nobis WP, Matthews RT, Winder DG (2008b) Dopamine enhances fast excitatory synaptic transmission in the extended amygdala by a CRF-R1-dependent process. J Neurosci 28:13856-13865. CrossRef Medline

Kash TL, Baucum AJ 2nd, Conrad KL, Colbran RJ, Winder DG (2009) Alcohol exposure alters NMDAR function in the bed nucleus of the stria terminalis. Neuropsychopharmacology 34:2420-2429. CrossRef Medline

Koob GF, Volkow ND (2010) Neurocircuitry of addiction. Neuropsychopharmacology 35:217-238. CrossRef Medline

Lê AD, Harding S, Juzytsch W, Watchus J, Shalev U, Shaham Y (2000) The role of corticotrophin-releasing factor in stress-induced relapse to alcohol-seeking behavior in rats. Psychopharmacology (Berl) 150: 317-324. CrossRef Medline

Leri F, Flores J, Rodaros D, Stewart J (2002) Blockade of stress-induced but not cocaine-induced reinstatement by infusion of noradrenergic antagonists into the bed nucleus of the stria terminalis or the central nucleus of the amygdala. J Neurosci 22:5713-5718. Medline

Lowery EG, Spanos M, Navarro M, Lyons AM, Hodge CW, Thiele TE (2010) CRF-1 antagonist and CRF-2 agonist decrease binge-like ethanol drinking in C57BL/6J mice independent of the HPA axis. Neuropsychopharmacology 35:1241-1252. CrossRef Medline

Macey DJ, Smith HR, Nader MA, Porrino LJ (2003) Chronic cocaine selfadministration upregulates the norepinephrine transporter and alters functional activity in the bed nucleus of the stria terminalis of the rhesus monkey. J Neurosci 23:12-16. Medline

Madisen L, Zwingman TA, Sunkin SM, Oh SW, Zariwala HA, Gu H, Ng LL, Palmiter RD, Hawrylycz MJ, Jones AR, Lein ES, Zeng H (2010) A robust and high-throughput Cre reporting and characterization system for the whole mouse brain. Nat Neurosci 13:133-140. CrossRef Medline

Marinelli PW, Funk D, Juzytsch W, Harding S, Rice KC, Shaham Y, Le AD (2007) The CRF1 receptor antagonist antalarmin attenuates yohimbineinduced increases in operant alcohol self-administration and reinstatement of alcohol seeking in rats. Psychopharmacology (Berl) 195:345-355. CrossRef Medline

Massi L, Elezgarai I, Puente N, Reguero L, Grandes P, Manzoni OJ, Georges F (2008) Cannabinoid receptors in the bed nucleus of the stria terminalis control cortical excitation of midbrain dopamine cells in vivo. J Neurosci 28:10496-10508. CrossRef Medline

Nobis WP, Kash TL, Silberman Y, Winder DG (2011) beta-Adrenergic receptors enhance excitatory transmission in the bed nucleus of the stria terminalis through a corticotrophin-releasing factor receptor-dependent and cocaine-regulated mechanism. Biol Psychiatry 69:1083-1090. CrossRef Medline
Olive MF, Koenig HN, Nannini MA, Hodge CW (2002) Elevated extracellular CRF levels in the bed nucleus of the stria terminalis during ethanol withdrawal and reduction by subsequent ethanol intake. Pharmacol Biochem Behav 72:213-220. CrossRef Medline

Pacak K, McCarty R, Palkovits M, Kopin IJ, Goldstein DS (1995) Effects of immobilization on in vivo release of norepinephrine in the bed nucleus of the stria terminalis in conscious rats. Brain Res 688:242-246. CrossRef Medline

Park J, Wheeler RA, Fontillas K, Keithley RB, Carelli RM, Wightman RM (2012) Catecholamines in the bed nucleus of the stria terminalis reciprocally respond to reward and aversion. Biol Psychiatry 71:327-334. CrossRef Medline

Radley JJ, Sawchenko PE (2011) A common substrate for prefrontal and hippocampal inhibition of the neuroendocrine stress response. J Neurosci 31:9683-9695. CrossRef Medline

Roberto M, Cruz MT, Gilpin NW, Sabino V, Schweitzer P, Bajo M, Cottone P, Madamba SG, Stouffer DG, Zorrilla EP, Koob GF, Siggins GR, Parsons LH (2010) Corticotropin releasing factor-induced amygdala gammaaminobutyric Acid release plays a key role in alcohol dependence. Biol Psychiatry 67:831-839. CrossRef Medline

Sinha R (2007) The role of stress in addiction relapse. Curr Psychiatry Rep 9:388-395. CrossRef Medline

Smith CC, Greene RW (2012) CNS dopamine transmission mediated by noradrenergic innervation. J Neurosci 32:6072-6080. CrossRef Medline

Taniguchi H, He M, Wu P, Kim S, Paik R, Sugino K, Kvitsiani D, Fu Y, Lu J, Lin Y, Miyoshi G, Shima Y, Fishell G, Nelson SB, Huang ZJ (2011) A resource of Cre driver lines for genetic targeting of GABAergic neurons in cerebral cortex. Neuron 71:995-1013. CrossRef Medline

Ulrich-Lai YM, Herman JP (2009) Neural regulation of endocrine and autonomic stress responses. Nat Rev Neurosci 10:397-409. CrossRef Medline

Veinante P, Stoeckel ME, Freund-Mercier MJ (1997) GABA- and peptideimmunoreactivities co-localize in the rat central extended amygdala. Neuroreport 8:2985-2989. CrossRef Medline

Wang J, Fang Q, Liu Z, Lu L (2006) Region-specific effects of brain corticotropin-releasing factor receptor type 1 blockade on footshockstress- or drug-priming-induced reinstatement of morphine conditioned place preference in rats. Psychopharmacology 185:19-28. CrossRef Medline

Wills TA, Klug JR, Silberman Y, Baucum AJ, Weitlauf C, Colbran RJ, Delpire E, Winder DG (2012) GluN2B subunit deletion reveals key role in acute and chronic ethanol sensitivity of glutamate synapses in bed nucleus of the stria terminalis. Proc Natl Acad Sci U S A 109:E278-E287. CrossRef Medline

You ZB, Wang B, Zitzman D, Azari S, Wise RA (2007) A role for conditioned ventral tegmental glutamate release in cocaine seeking. J Neurosci 27:10546-10555. CrossRef Medline 